\title{
Research on Influencing Factors of Equipment Asset Performance Evaluation Level of Regional Distribution Network Based on Interpretive Structure Model
}

\author{
Wang Zheng ${ }^{1}$, Gu Zhihong ${ }^{* 1}$, Xin Xiaoxia ${ }^{1}$, Wen Wei ${ }^{1}$ \\ ${ }^{1}$ State Grid Shanxi Economic Research Institute, 030002, China
}

\begin{abstract}
The evaluation of equipment asset performance level of regional distribution network is an important link. As the equipment assets of the regional distribution network are affected by many factors, the performance level is low. Based on this, this paper considers 11 influencing factors from the two dimensions of cost input impact and performance output impact, establishes a model of the interpretation structure of the equipment asset performance level of the regional distribution network, and conducts detailed analysis and discussion. The results show that more attention needs to be paid to key factors such as the emission reduction rate of coal-to-electricity projects, annual conventional power grid construction investment costs, coal-to-electricity project investment, annual conventional grid operation and maintenance costs, and electricity sales revenue, which will help improve the performance level of equipment assets in the regional distribution network.
\end{abstract}

\section{Introduce}

With the gradual advancement of the new strategic thinking by the State Grid, the investment in the construction of the distribution network has gradually expanded. In 2019, the company's investment quota reached about 450 billion yuan, a year-on-year increase of $4.8 \%$. As an important link of the regional power grid and an indispensable infrastructure for urban and rural development, the distribution network plays a pivotal role in undertaking construction tasks ${ }^{[1]}$. Although the power supply reliability of my country's distribution network has improved significantly, the overall level of development is still relatively weak, and the level of urban-rural and regional development is uneven, resulting in low performance of regional distribution network equipment assets. Therefore, in order to improve the performance level of equipment assets of the regional distribution network, it is necessary to deeply analyze the impact of different dimensions, which is conducive to making targeted improvement suggestions and strategies.

Many scholars have conducted research on the performance level of equipment assets of regional distribution network. Hao et al. [2] through in-depth analysis of the development characteristics of China's distribution network and the differences in user needs, using users and the distribution network as the interface, have constructed a comprehensive performance evaluation system for asset life cycle management that covers economy, service efficiency and social benefits. He et al. [3] built a distribution network investment distribution model based on the comprehensive performance evaluation results of the whole life cycle and constructed a distribution network investment distribution model according to the comprehensive distribution network investment development strategy to allocate different distribution network investments. Gu et al. [4] combined the specific feeders in the distribution network to analyze the investment income, and deeply explored the profitability of the existing distribution network assets and the key factors affecting the asset income. Zhou et al. [5] established a three-level indicator system for power development level evaluation from five aspects: economic energy coordination, power generation level, power consumption level, power supply level and power development potential. Chen et al. [6] took the distribution grid management as the scenario, established a distribution network hierarchical partition evaluation model based on the three-level grid of power supply unit, power supply grid, and power supply partition, and following the working ideas led by the plan, proposed a key performance indicator (KPI) system for the distribution network with "planning target line achievement rate" as the core. Li et al. [7] analyzed the core performance elements of the energy-saving transformation of the distribution network based on the key performance indicator (KPI: Key Performance

\footnotetext{
*Corresponding author: 381593857@qq.com
} 
Indicator) theory: efficiency, effectiveness, and benefit, and used the principal component analysis method and the optimal judgment matrix method to screen the indicators, thereby constructing an index system for comprehensive effectiveness evaluation, and based on the KPI theory, proposed a quantitative evaluation method for the comprehensive effectiveness of the energy-saving transformation of the distribution network to achieve accurate evaluation of the comprehensive effectiveness of the energy-saving transformation of the distribution network. The above studies have evaluated the influencing factors of the performance evaluation level of the distribution network from different dimensions. However, as the investment in the distribution network increases year by year, the problems of its variety of equipment, large size, rough management and insufficient information have become more prominent. Few studies involve the correlation between the various influencing factors.

Therefore, this paper uses the explanatory structure model to establish matrix relationships and calculations on the factors affecting the performance of the regional distribution network, constructs a hierarchical structure diagram between the influencing factors, and selects a regional distribution network for example analysis. The analysis shows the structural relationship between the various influencing factors, and provides suggestions and guidance for other research.

\section{Identify the influencing factors of performance evaluation level}

By collecting relevant literature and research results, this paper summarizes 11 influencing factors that affect the performance of regional distribution network equipment assets [8]. On this basis, 25 experts in the related fields of distribution network were invited to judge and identify the above-mentioned influencing factors. The information of some invited experts is shown in Table 1.

Table 1 Invite expert information

\begin{tabular}{ccccc}
\hline Expert & Job title & $\begin{array}{c}\text { Educati } \\
\text { on }\end{array}$ & $\begin{array}{c}\text { Working } \\
\text { years }\end{array}$ & $\begin{array}{c}\text { Working } \\
\text { Organization }\end{array}$ \\
\hline exp-I & $\begin{array}{c}\text { Senior } \\
\text { engineer }\end{array}$ & Postdoc & 16 years & EPPI \\
\hline exp -II & $\begin{array}{c}\text { Senior } \\
\text { engineer }\end{array}$ & Postdoc & 11 years & SGREI \\
\hline exp -III & professor & doctor & 15 years & BJTU \\
\hline exp -IV & professor & Postdoc & 24 years & NCEPU \\
\hline exp - V & $\begin{array}{c}\text { Senior } \\
\text { engineer }\end{array}$ & doctor & 14 years & SGSEPC \\
\hline
\end{tabular}

After the evaluation of the above-mentioned experts, the judgment result of the factors influencing the summarized regional distribution network equipment asset performance level can be obtained. The performance level of equipment assets of the distribution network uses the input-output theory to further observe the performance level of equipment assets of the distribution network. Therefore, by combining the influencing factors mentioned in Table 2, the inputoutput theory is used to classify the influencing factors of regional distribution network equipment assets, as follows:

\subsection{Factors affecting cost input}

The influencing factors of the cycle cost input of the distribution network, which are based on the idea of asset life cycle management, mainly considers five factors of the annual conventional grid construction input cost, annual conventional grid operation and maintenance cost, coal-to-electricity project input, electric vehicle grid-connected investment and new energy grid-connected Invest. Among them, the annual conventional power grid construction investment cost and operation and maintenance cost can be converted to each year according to the net present value to calculate the annual cost. At the same time, with the gradual implementation of coal-to-electricity projects, the promotion of grid vehicles, and the integration of new energy sources, the investment cost of the distribution network has increased to a large extent, and it will also be an important factor in the evaluation of the performance level of regional distribution network equipment assets.

\subsection{Influencing factors of performance output}

In order to take into account economic, social and service efficiency, the factors affecting the comprehensive performance and output of the distribution network mainly consider the income from electricity sales, service capacity, service quality, the emission reduction rate of coal-to-electricity projects, electric vehicle access emission reduction rate and new energy grid-connected power generation emission reduction rate. Among them, the income from electricity sales is a direct reflection of the annual electricity collection and electricity sales income of the distribution network, which is the most important embodiment of economic benefits. Service capability characterizes the ability of the distribution network system to serve various users. Service quality reflects the quality of service provided by the distribution network to users, mainly including voltage quality and reliability quality, and reflects the comprehensive level of grid equipment, structure, management, and intelligence. Factors such as coal-to-electricity projects, electric vehicle access, and new energy grid integration is to achieve regional energy saving and emission reduction effects, and the $\mathrm{CO} 2$ emission reduction achieved by replacing thermal power with clean energy power generation is proportional to the amount of clean energy power generation. 


\section{Interpretation structure model construction of factors affecting performance level}

\subsection{Interpretive Structure Model Idea}

In the $1970 \mathrm{~s}$, in order to solve the complexity problem, John N. Warfield first proposed the concept of interpretive structure model (ISM) [9]. This method decomposes a complex system into several subsystem elements, and uses practical experience, knowledge and the help of computers to form a multi-level hierarchical structure model. It mainly focuses on qualitative analysis, transforms vague thoughts into intuitive and good structural relationships, and is suitable for system analysis with numerous variables, complex relationships and unclear structures.

After determining the influencing factors of the equipment asset performance level of the regional distribution network from the previous section, the hierarchical structure between the influencing factors is further divided. This paper uses an explanatory structure model to analyze the influencing factors of the equipment asset performance level of the regional distribution network, divides it into a hierarchical structure, and identifies the surface influencing factors, specific influencing factors and in-depth influencing factors, as well as the relationship between levels.

\subsection{Interpretation structure model construction of factors affecting performance level}

Based on the idea of explanatory structure model, an explanatory structure model of the factors affecting the performance level of equipment assets of the regional distribution network can be constructed, as follows:

(1) Determine the relationship between the impact of performance level

The 11 influencing factors in the evaluation of the performance of equipment assets of the regional distribution network are based on inviting experts to clarify the interaction between each other, and the specific determination rules are: (1) $V$ :Factor $i$ has a direct impact on factor $j$; (2) $A$ :Factor $j$ has a direct impact on factor $i$; $X$ : Factor $i$ and factor $j$ directly influence each other; (4) $O$ : No influence relationship between factor $i$ and factor $j$.

(2) Following the judgment rules, the adjacency matrix $a$ and the reachable matrix $b$ of the factors affecting the performance level can be obtained. Among them, the reachable matrix represents the connection channel from one factor to another, and is the data interpretation of the hierarchical structure model, which is used to express the influence relationship existing between all the constituent elements.

(3) Hierarchical structure division and model construction of factors affecting performance level
Hierarchical structure division requires inter-level decomposition, and hierarchical construction is based on the order of decomposition results. Inter-level decomposition is to divide all elements into several levels after decomposition based on the reachability matrix, which is used to build a hierarchical structure of factors affecting performance.

(4) Structural model analysis of factors affecting performance level

According to the results of the hierarchical structure of the influencing factors of performance level, the driving-dependence analysis method is used to further analyze the relationship between the various levels, to obtain the driving force and dependence of each influencing factor, and to point out the surface influencing factors, specific influencing factors and deep-seating influences on performance.

\subsection{The specific calculation process of building the model}

According to the construction of the interpretation structure model of the influencing factors of the performance level, the hierarchical structure of the influencing factors is obtained. The specific analysis process is shown in Figure 1.

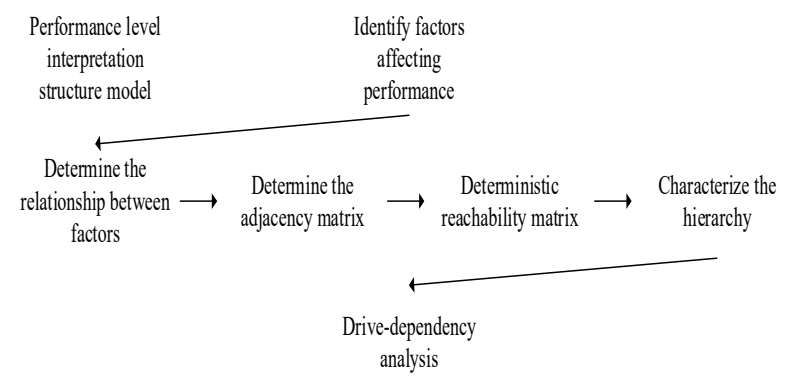

Fig 1 Performance level explanation structure model flow chart

\section{Case Analysis}

In order to verify the effectiveness of the proposed performance level interpretation structure model, a regional distribution network is selected for analysis.

\subsection{Determine the influencing factors of performance level}

The influencing factors of the above performance level are expressed by $\left\{F_{i}, i=1,2, \ldots, 11\right\}$, namely: $F_{1}$ is the annual conventional grid construction investment cost, $F_{2}$ is the annual conventional grid operation and maintenance cost, $F_{3}$ is the coal-to-electricity project investment, $F_{4}$ is the electric vehicle grid-connected investment, $F_{5}$ is new energy grid-connected investment, $F_{6}$ is electricity sales revenue, $F_{7}$ is service capacity, $F_{8}$ is service quality, $F_{9}$ is coal-to-electricity project 
emission reduction rate, $F_{10}$ is electric vehicle access emission reduction rate, and $F_{11}$ is new energy gridconnected power generation reduction rate.

\subsection{Determine adjacency matrix and reachability matrix}

According to the evaluation results of invited experts and the judgment rules of the factors affecting the performance level, the specific adjacency matrix $A$ is:

$A=\left[\begin{array}{lllllllllll}0 & 0 & 0 & 1 & 0 & 0 & 0 & 0 & 0 & 0 & 1 \\ 0 & 0 & 0 & 1 & 0 & 0 & 0 & 0 & 0 & 0 & 0 \\ 0 & 0 & 0 & 1 & 0 & 0 & 0 & 0 & 0 & 0 & 0 \\ 0 & 1 & 0 & 0 & 0 & 0 & 0 & 0 & 0 & 0 & 0 \\ 1 & 0 & 0 & 1 & 0 & 0 & 1 & 0 & 0 & 0 & 0 \\ 0 & 0 & 0 & 1 & 0 & 0 & 1 & 0 & 1 & 1 & 0 \\ 0 & 1 & 0 & 0 & 0 & 0 & 0 & 0 & 0 & 1 & 0 \\ 1 & 1 & 0 & 0 & 1 & 0 & 0 & 0 & 0 & 0 & 1 \\ 0 & 0 & 0 & 0 & 0 & 1 & 0 & 0 & 1 & 0 & 0 \\ 0 & 0 & 0 & 1 & 0 & 0 & 0 & 0 & 0 & 0 & 0 \\ 0 & 1 & 0 & 0 & 0 & 0 & 1 & 0 & 0 & 0 & 0\end{array}\right]$

After the budget rule, the reachable matrix $R$ is:

$$
R=\left[\begin{array}{lllllllllll}
1 & 1 & 1 & 1 & 0 & 1 & 1 & 0 & 1 & 1 & 0 \\
1 & 0 & 1 & 0 & 0 & 0 & 1 & 1 & 1 & 1 & 1 \\
1 & 1 & 1 & 1 & 1 & 0 & 1 & 1 & 1 & 1 & 0 \\
0 & 1 & 0 & 1 & 1 & 1 & 0 & 0 & 0 & 1 & 1 \\
0 & 1 & 0 & 1 & 1 & 1 & 1 & 0 & 0 & 1 & 1 \\
0 & 0 & 1 & 0 & 0 & 0 & 1 & 1 & 0 & 0 & 1 \\
0 & 1 & 1 & 0 & 0 & 1 & 1 & 1 & 1 & 1 & 0 \\
0 & 1 & 1 & 0 & 1 & 1 & 1 & 1 & 1 & 0 & 0 \\
0 & 0 & 1 & 0 & 0 & 1 & 1 & 0 & 1 & 1 & 0 \\
0 & 1 & 0 & 1 & 1 & 0 & 1 & 0 & 1 & 1 & 1 \\
0 & 1 & 0 & 1 & 1 & 1 & 0 & 1 & 0 & 1 & 1
\end{array}\right]
$$

\subsection{Determine the hierarchy of factors affecting performance level}

According to the order of the decomposition results, the hierarchical structure of the factors affecting the performance level can be obtained. The first level is shown in Table 2:

Table 2 The first level of influencing factors of performance level

\begin{tabular}{|c|c|c|c|l|}
\hline$F_{i}$ & $R\left(F_{i}\right)$ & $A\left(F_{i}\right)$ & $R\left(F_{i}\right) \cap A\left(F_{i}\right)$ & first \\
\hline 1 & $1,3,7,9,10$ & $1,2,3$ & 1,3 & \\
\hline 2 & $1,2,3,7$ & $2,3,9,10$ & 2,3 & \\
\hline 3 & $1,3,9,10$ & $6,7,9$ & 9 & \\
\hline 4 & $4,5,6,10,11$ & $1,3,4,5,10,11$ & $4,5,10,11$ & \\
\hline 5 & $4,5,7,10,11$ & $3,4,5,6,10,11$ & $4,5,10,11$ & \\
\hline 6 & $2,3,6,9$ & $2,3,6,8$ & $2,3,6$ & \\
\hline 7 & 7,8 & $1,3,4,5,7,8,10,11$ & 7,8 & I \\
\hline 8 & 7,8 & $1,4,4,7,7,8,9$ & 7,8 & I \\
\hline 9 & 7,9 & $7,9,10$ & 7,9 & \\
\hline
\end{tabular}

\begin{tabular}{|c|c|c|c|c|}
\hline 10 & $4,5,10,11$ & $1,4,5,7,9,10,11$ & $4,5,10,11$ & \\
\hline 11 & $4,5,8,10,11$ & $1,3,4,5,10,11$ & $4,5,10,11$ & \\
\hline
\end{tabular}

It can be obtained that the first-level influencing factors are $F_{2}$ and $F_{6}$, and the second-level influencing factors can be obtained by further calculation, as shown in Table 3:

Table 3 The second level of influencing factors of performance level

\begin{tabular}{|c|c|c|c|c|}
\hline$F_{i}$ & $R\left(F_{i}\right)$ & $A\left(F_{i}\right)$ & $R\left(F_{i}\right) \cap A\left(F_{i}\right)$ & second level \\
\hline 1 & $1,3,9,10$ & $1,2,3$ & 1,3 & \\
\hline 2 & $1,2,3$ & $2,3,9,11$ & 2,3 & \\
\hline 3 & $1,3,9,11$ & 8,9 & 9 & \\
\hline 4 & $4,5,10,11$ & $1,3,4,5,10,11$ & $4,5,10,11$ & II \\
\hline 5 & $4,5,10,11$ & $3,4,5,8,10,11$ & $4,5,10,11$ & II \\
\hline 6 & $2,3,6,9$ & $2,3,6$ & $2,3,6$ & \\
\hline 9 & 9 & 9,10 & 9 & II \\
\hline 10 & $4,5,10,11$ & $1,4,5,9,10,11$ & $4,5,10,11$ & \\
\hline 11 & $4,5,10,11$ & $1,3,4,5,10,11$ & $4,5,10,11$ & \\
\hline It & & & & \\
\hline
\end{tabular}

It can be obtained that the second-level influencing factors are $F_{4} 、 F_{5} 、 F_{10} 、 F_{11}$, and further calculations can be used to obtain the third-level influencing factors, as shown in Table 4:

Table 4 The third level of influencing factors of performance level

\begin{tabular}{|c|c|c|c|c|}
\hline$F_{i}$ & $R\left(F_{i}\right)$ & $A\left(F_{i}\right)$ & $R\left(F_{i}\right) \cap A\left(F_{i}\right)$ & third level \\
\hline 1 & $1,3,9$ & $1,2,3$ & 1,3 & \\
\hline 2 & $1,2,3$ & $2,3,9$ & 2,3 & \\
\hline 3 & $1,3,9$ & $1,2,3$ & 1,3 & \\
\hline 6 & $2,3,6,9$ & 3,6 & 3,6 & \\
\hline 9 & 9 & 9 & 9 & III \\
\hline
\end{tabular}

It can be obtained that the third-level influencing factor is $F_{9}$, and the fourth-level influencing factors can be obtained by further calculation, as shown in Table 5:

Table 5 The fourth level of influencing factors of performance

\begin{tabular}{|c|c|c|c|c|}
\hline$F_{i}$ & $R\left(F_{i}\right)$ & $A\left(F_{i}\right)$ & $R\left(F_{i}\right) \cap A\left(F_{i}\right)$ & The fourth level \\
\hline 1 & 1,3 & $1,2,3$ & 1,3 & IV \\
\hline 2 & $1,2,3$ & 2,3 & 2,3 & \\
\hline 3 & 1,3 & $1,2,3$ & 1,3 & IV \\
\hline 6 & $2,3,6$ & 3,6 & 3,6 & \\
\hline
\end{tabular}

From this it can be obtained that the fourth-level influencing factors are $F_{1} 、 F_{3}$, and further calculations 
can be used to obtain the fifth-level influencing factors, as shown in Table 6:

Table 6 The fifth level of influencing factors of performance level

\begin{tabular}{|c|c|c|c|c|}
\hline$F_{i}$ & $R\left(F_{i}\right)$ & $A\left(F_{i}\right)$ & $R\left(F_{i}\right) \cap A\left(F_{i}\right)$ & fifth level \\
\hline 2 & 2 & 2 & 2 & $\mathrm{~V}$ \\
\hline 6 & 6 & 6 & 6 & $\mathrm{~V}$ \\
\hline
\end{tabular}

It can be concluded that the fifth-level influencing factor is $F_{7} 、 F_{8}$.

\subsection{Draw the hierarchical structure of each influencing factor of performance level}

Based on the various influencing factors of the performance level calculated in the previous section, the corresponding hierarchical structure can be drawn, as shown in Figure 2:

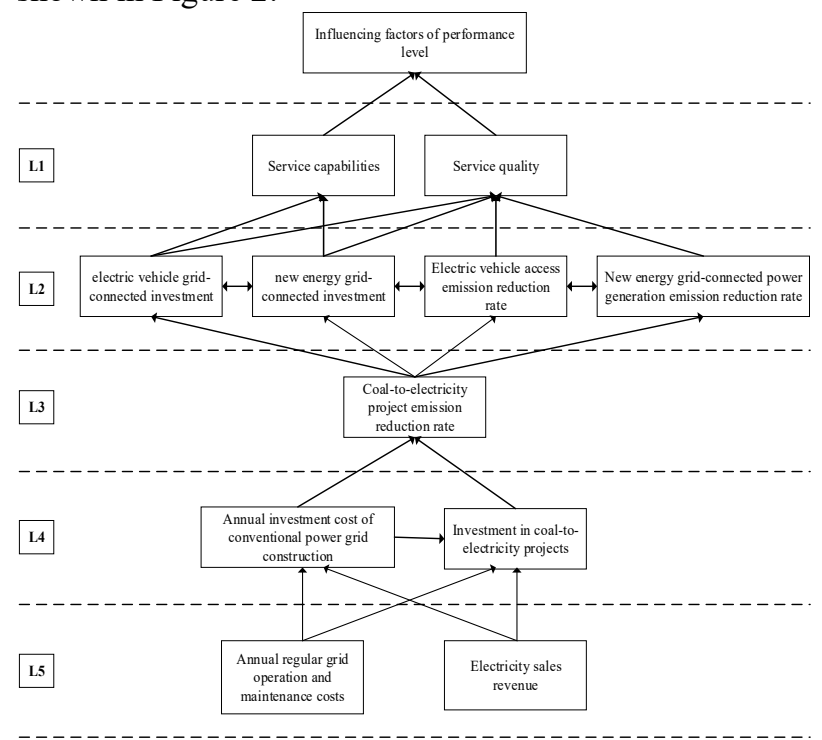

Fig 2 Hierarchical structure of performance levels

After a series of calculations, it can be seen that service capabilities and service quality are the surfacelevel influencing factors; electric vehicle grid-connected investment, new energy grid-connected investment, electric vehicle access emission reduction rate and new energy grid-connected power generation emission reduction rate are the target level impact Factors: The emission reduction rate of coal-to-electricity projects, annual investment cost of conventional power grid construction, investment of coal-to-electricity projects, annual operation and maintenance costs of conventional power grids, and electricity sales revenue are key influencing factors.

\section{Conclusion}

There are many factors influencing the performance level of equipment assets in the regional distribution network. This article divides it into levels with the help of an explanatory structure model, and the results are helpful to propose targeted guidance suggestions. At the same time, China's distribution network equipment asset management has been developing for a period of time, but there are still many problems, resulting in a mismatch between investment costs and returns. The results obtained in this article can only give one direction, and there are also imperfections. The research will urgently need in-depth discussion and consideration.

\section{Acknowledgement}

Project Supported by Research on device asset performance evaluation model and configuration optimization technology of Shanxi distribution network under Energy Internet (SGTYHT/18-JS-206).

\section{Reference}

1. Seyed Ali Mohajeran,et al. J-divergence-based Power Allocation in Wireless Sensor Networks with Distributed Detection under Correlated Noises[J]. International Journal of Communication Systems, 2020, 33(14).

2. HAO Yongkang, LIU Wenxia, et al. Comprehensive Performance Evaluation Method for Asset Management of Distribution Network Considering $[\mathrm{J}]$. Modern Electric Power, 2019,36(04):79-87.

3. HE Chengchun, MA Guoxiang, et al. Research on Comprehensive Performance Evaluation System of Distribution Asset Management[J]. Qinhai Electric Power, 2017,36(04):69-72.

4. GU Ren, CHEN Jun, et al. Evaluation Model for Investment Income of Distribution Network and Its Application[J]. Smart Grid, 2017,5(05):480-486.

5. ZHOU Yifan ,HU Wei, et al. Dynamic Comprehensive Evaluation Method of Power Industry Development Level Based on Provincial Data[J]. Automation of Electric Power Systems, 2016,40(18):76-83.

6. Chen Chaoyang, Jin Bowen, et al. Research on the Key Performance Index (KPI) System of Distribution Network in the Grid of Distribution[J]. Electric Power Equipment Management, 2019(10):38-40.

7. Li Yan, Xu Wenyang, et al. Research on Comprehensive Effectiveness Evaluation of Energy Efficiency Reconstruction of Distribution Network Based on KPI Theory[J]. Value Engineering, 2018,37(36):64-65.

8. Zhao Mengya, Liang Zhirui. The analysis on the influence factors of TV fuses blowing in the distribution network[J]. Electrical Measurement \& Instrumentation, 2016,53(21):76-81.

9. Shahryar Sarabi, Qi Han,A. et al. Uptake and implementation of Nature-Based Solutions: An analysis of barriers using Interpretive Structural Modeling[J]. Journal of Environmental Management, 2020,270. 